\title{
On the Optimal Use of Ex Ante Regulation and Ex Post Liability*
}

\author{
Yolande Hiriart ${ }^{\dagger} \quad$ David Martimort ${ }^{\ddagger} \quad$ Jerome Pouyet $^{\S}$ \\ 2nd March 2004
}

\begin{abstract}
We build on Shavell (1984)'s analysis of the optimal use of ex ante and ex post interventions when a firm engages into activities potentially risky for the environment or third-parties and has private information about the level of the damage. The regulator enforces ex ante a standard of precautionary effort but is uninformed about the harm level; ex post, in the event of an accident, the judge may bring a lawsuit and discover the harm level. The social optimum can be reached if, ex ante, the regulator offers the firm a menu of incentive contracts (rewards, penalties and verifiable standards). When the precautionary effort is no longer verifiable, the inefficiencies generated by the moral hazard incentive problem cannot be circumvented.
\end{abstract}

JEL Classification: K13, K32, L51.

Keywords: Ex Ante Regulation, Ex Post Liability.

\section{Introduction}

Shavell (1984) provides a pioneering analysis of two distinct and often-encountered instruments in environmental policies: ex ante regulation and ex post legal intervention. Three actors are involved: a firm with limited assets which undertakes an

*This paper is part of a research program between IDEI and the French Ministry of Ecology and Sustainable Development on the regulation of risky industrial activity. Financial and intellectual support from the Ministry of Ecology and Sustainable Development are gratefully acknowledged. We wish to thank the Editor, Eric Maskin, and an anonymous referee for their helpful comments.

${ }^{\dagger}$ University of Toulouse (IDEI, LEERNA). Address: LEERNA-IDEI, Manufacture des Tabacs, Bat. F, 21 Allée de Brienne, 31000 Toulouse, FrANCE. E-mail: yhiriart@cict.fr.

${ }^{\ddagger}$ Author for correspondence. University of Toulouse (IDEI, GREMAQ) and Institut Universitaire de France. Address: IDEI, Manufacture des Tabacs, Bat. F, 21 Allée de Brienne, 31000 Toulouse, FrANCE. Phone: +33 (0)561128614. Fax: +33 (0)561128637. E-mail: martimor@cict.fr.

${ }^{\S}$ CREST-LEI, University of Toulouse (IDEI), CERAS-ENPC and CEPR. Address: ENPC, LEI, 28 rue des Saints-Pères, 75007 Paris, FrAnCE. E-mail: pouyet@ensae.fr 
environmentally risky activity, thereby potentially causing harm to third-parties; a regulator, who intervenes ex ante and enforces a verifiable standard of precautionary effort for the firm which affects the probability of an accident; a judge who may impose a fine on the firm after an accident has occurred. Shavell shows that the optimal regulation consists in setting a standard of care which equals the firm's marginal disutility with the expected damage. The benefit of using the judge comes from the possibility of discovering the value of this damage when a legal suit is undertaken and to improve incentives conditional on this event. We extend Shavell (1984)'s analysis by allowing ex ante regulatory transfers which are socially costly. The first-best level of care depends on the damage level and can now be easily implemented when care is observable and a standard can be used. When care is non-observable, the optimal precautionary care depends only on the expected damage and no longer on the realized damage. It is no longer first-best.

\section{Setting the stage}

Consider a firm which undertakes a risky activity. The probability of an accident is $1-e$ where $e$ is a precautionary effort exerted by the firm at a cost $\psi(e)\left(\psi^{\prime}, \psi^{\prime \prime}>0\right)$. In the event of an accident, third-parties suffer from a damage whose magnitude is $h$. Possible levels of the damage belong to $[\underline{h}, \bar{h}]$. The first-best effort level depends on the size of the damage and is given by $\psi^{\prime}\left(e^{*}(h)\right)=h$. At the margin, the optimal effort level must trade off the gain associated with a smaller accident probability, and consequently a lower expected damage on third-parties, with a larger cost of precaution for the firm.

Assume that the firm has limited assets $y<h$ and is privately informed about $h$. When an accident occurs, the judge engages a lawsuit against the firm with an exogenous probability given by $q \in[0,1]$. The judge will be able to discover $h$ only if a lawsuit is engaged. The regulator can enforce a given standard of precautionary effort $s$. In this context, Shavell (1984) studies the joint use of regulation and liability by a merged regulatory entity. Since ex ante transfers to the firm are ruled out, the merged entity obtains information on harm only when an ex post intervention is used and an ex ante standard is useful otherwise. The level of care depends then on $h$ only because of the ex post intervention. With ex ante transfers, we show that the only role for the judge is to make incentives to reveal information on $h$ strict when care is observable and a standard can be used. Using the judge is irrelevant when care is non-observable. In this case, the optimal regulatory policy cannot be contingent on the level of harm. 


\section{Observable precautionary effort}

Invoking the Revelation Principle, there is no loss of generality in restricting the merged entity to offer a direct and truthful menu of contracts to the privately informed firm. This menu consists of a standard $s(\hat{h})$, a transfer in case of an accident (respectively, no accident) $t_{a}(\hat{h})$ (respectively, $t_{n}(\hat{h})$ ), which all depend on the firm's announcement $\hat{h}$ of the value of the damage. This contract also stipulates a penalty $R(\hat{h}, h)$ if the firm has announced ex ante $\hat{h}$ to the regulator and the judge discovers ex post that the true damage is $h$ (with $R(h, h)=0) .{ }^{1}$

The following incentive constraints must thus hold: for all pairs $(h, \hat{h})$

$$
\begin{aligned}
& U(h, h) \equiv s(h) t_{n}(h)+(1-s(h)) t_{a}(h)-\psi(s(h)) \geq \\
& U(\hat{h}, h) \equiv s(\hat{h}) t_{n}(\hat{h})+(1-s(\hat{h}))\left[(1-q) t_{a}(\hat{h})+q\left(t_{a}(\hat{h})-R(\hat{h}, h)\right)\right]-\psi(s(\hat{h})) .
\end{aligned}
$$

Given the restricted liability of the firm, the following limited liability constraints have to be satisfied by the contract: for all pairs $(h, \hat{h})$

$$
\begin{aligned}
& t_{a}(\hat{h})-R(\hat{h}, h) \geq-y, \\
& t_{a}(\hat{h}), t_{n}(\hat{h}) \geq-y .
\end{aligned}
$$

Finally, the firm accepts the contract if its individual rationality constraints are satisfied: for all pairs $(h, h)$

$$
U(h, h) \geq 0 .
$$

The regulator's objective ${ }^{2}-(1-s(h)) h-s(h) t_{n}(h)-(1-s(h)) t_{a}(h)=-(1-$ $s(h)) h-\psi(s(h))-U(h, h)$ is maximized when the firm receives no rent (i.e., $U(h, h)=$ $0)$ and the standard is set at the first-best level of care, i.e., $s^{*}(h)=e^{*}(h)$.

To relax incentive constraints under asymmetric information on $h$, the penalty $R(\hat{h}, h)$ should be set at the highest value consistent with the limited liability constraints of the firm: $\left(L L_{1}\right)$ is binding at equilibrium. Is it possible to implement the socially optimal standard while leaving the firm with no rent and ensuring incentive compatibility? This amounts to finding a set of transfers such that, for all $h$

$$
\begin{aligned}
& s^{*}(h) t_{n}(h)+\left(1-s^{*}(h)\right) t_{a}(h)-\psi\left(s^{*}(h)\right)=0, \\
& s^{*}(h) t_{n}(h)+\left(1-s^{*}(h)\right)\left[(1-q) t_{a}(h)-q y\right]-\psi\left(s^{*}(h)\right) \leq 0, \\
& t_{a}(h), t_{n}(h) \geq-y .
\end{aligned}
$$

\footnotetext{
${ }^{1}$ This game features adverse selection with ex post arrival of correlated information, as studied in Riordan and Sappington (1988), with the following differences: the probability of occurrence of the ex post information depends on the contract itself and, more importantly, the adverse selection parameter $h$ does not affect directly the firm's utility.

${ }^{2}$ Note that regulatory transfers are costly.
} 
Simple algebra reveals that such transfers always exist. Indeed, taking into account that (1) holds, the incentive constraint (2) becomes $q\left(1-s^{*}(h)\right)\left[t_{a}(h)+y\right] \geq 0$ and it is implied by (3).

To explain this result, consider first the case of regulation alone, i.e., $q=0$. In this case, the true harm level is never discovered ex post. However, the regulator can offer a menu of contracts such that, for each possible value of $h$, the standard is first-best and the transfers $t_{a}(h)$ and $t_{n}(h)$ are such that $U(h, h)=0$. Faced with this menu, the firm knowing $h$ is exactly indifferent between announcing $h$ or $\hat{h} \neq h$ to the regulator since in both cases it gets no rent. This stems from the fact that the firm's private information does not enter directly into its objective function but only indirectly through the mechanism offered by the regulator. If this indifference could be broken in favor of the regulator, then there would be no gain to complement ex ante regulation with ex post liability rules. The joint use of ex ante regulation and ex post liability ensures that the firm has a strict incentive to reveal its information. Then, (2) is a strict inequality. Indeed, if it lies, the firm runs the risk of being caught ex post if a lawsuit is engaged and the true harm level is revealed. ${ }^{3}$

\section{Unobservable precautionary effort}

Consider now that, on top of the adverse selection incentive problem, the joint entity cannot observe the precautionary effort, which is now chosen by the firm in order to maximize its utility. No standard can be imposed because care is non-observable. In a truthful equilibrium, the following (first-order) moral hazard constraint must be satisfied

$$
t_{n}(h)-t_{a}(h)=\psi^{\prime}(e(h))
$$

where $e($.$) denotes now the effort level. When the firm has enough wealth (typically$ $y>\bar{h}$ ), the regulator overcomes the moral hazard problem by creating sufficiently large a wedge between the transfers in the event of an accident and of no accident. Neither the nonobservability of the precautionary effort nor the adverse selection problem create inefficiencies. ${ }^{4}$

However, when $y<\underline{h}$, the limited wealth constraint always binds and $t_{a}(h)=-y .^{5}$ Ex post legal intervention turns out to be useless. In the event of an accident, which occurs with probability $1-e(\hat{h}), t_{a}(\hat{h})=-y$ and thus $R(\hat{h}, h)=0$ so that the firm not revealing truthfully its information earns $(1-q) t_{a}(\hat{h})+q\left[t_{a}(\hat{h})-R(\hat{h}, h)\right]=-y$, which no longer depends on the probability of the judge's intervention. The regulator must

\footnotetext{
${ }^{3}$ Note that it is possible for the regulator to offer the firm a transfer only if there is no accident or only when an accident has occurred.

${ }^{4}$ The proof of this statement is immediate and left to the reader.

${ }^{5} \mathrm{It}$ is standard to show that this is the relevant limited liability constraint.
} 
now give to the firm a socially costly liability rent $U(h) \equiv-y+e(h) \psi^{\prime}(e(h))-\psi(e(h))$ to induce care. The regulator can no longer choose transfers so that adverse selection incentive compatibility constraints are satisfied at no cost. The adverse selection constraint writes indeed as $U(h) \geq U(\hat{h})$ for all pairs $(h, \hat{h})$. This implies that the same level of rent must be given to the firm ${ }^{6}$ whatever its information on the damage, and that $t_{n}(h)$ (and thus $s(h)$ from $\left.(4)\right)$ are independent of $h$.

Regulatory transfers are used to induce the firm to internalize the effects of its actions and to partially realign the social and private incentives but do not allow for information revelation.

In this context, moral hazard truly magnifies the adverse selection problem and leads to socially costly inefficiencies. Under moral hazard for the precautionary effort and adverse selection on the harm level, no information revelation occurs and ex post intervention is useless. The effort level $e^{p}$ induced by an optimal regulation with ex ante transfers depends only on the expected damage:

$$
\mathbb{E}(h)=\psi^{\prime}\left(e^{p}\right)+e^{p} \psi^{\prime \prime}\left(e^{p}\right) .
$$

\section{References}

Lewis, T. and D. Sappington, 2000, "Contracting with Wealth-Constrained Agents", International Economic Review, 41: 743-767.

Riordan, M. and D. Sappington, 1988, "Optimal Contracts with Public Ex Post Information", Journal of Economic Theory, 45: 189-199.

Shavell, S., 1984, "A Model of the Optimal Use of Liability and Safety Regulation", RAND Journal of Economics, 15: 271-280.

${ }^{6}$ See Lewis and Sappington (2000) for a related model. 